\title{
Le Thesaurus de l'Image Médicale de Strasbourg 025
}

European Journal of

Orthopaedic Surgery \&

Traumatology

Eur J Orthop Surg Traumatol (1998) 8: 151

(C) Springer-Verlag 1998

A. Wackenheim ${ }^{\dagger}$

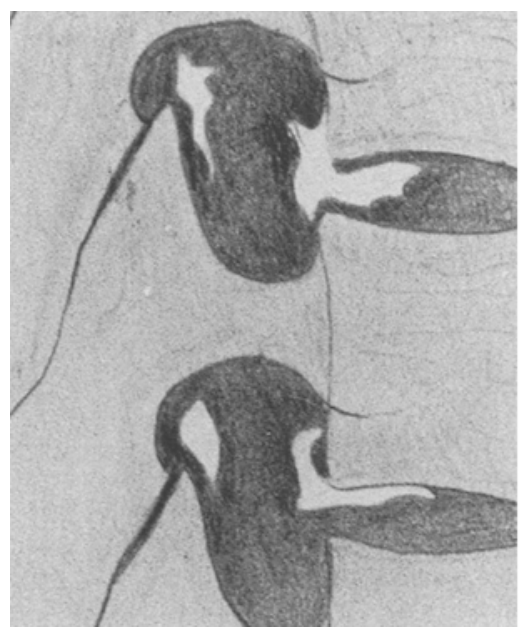

F66

Chondrocalcinosis of vertebral discs and ligaments (P) (RX)

Chondrocalcinose disco-ligamentaire du rachis (P) (RX)

Chondrokalzinose der Wirbelbänder und Bandscheiben (P) (Rö)
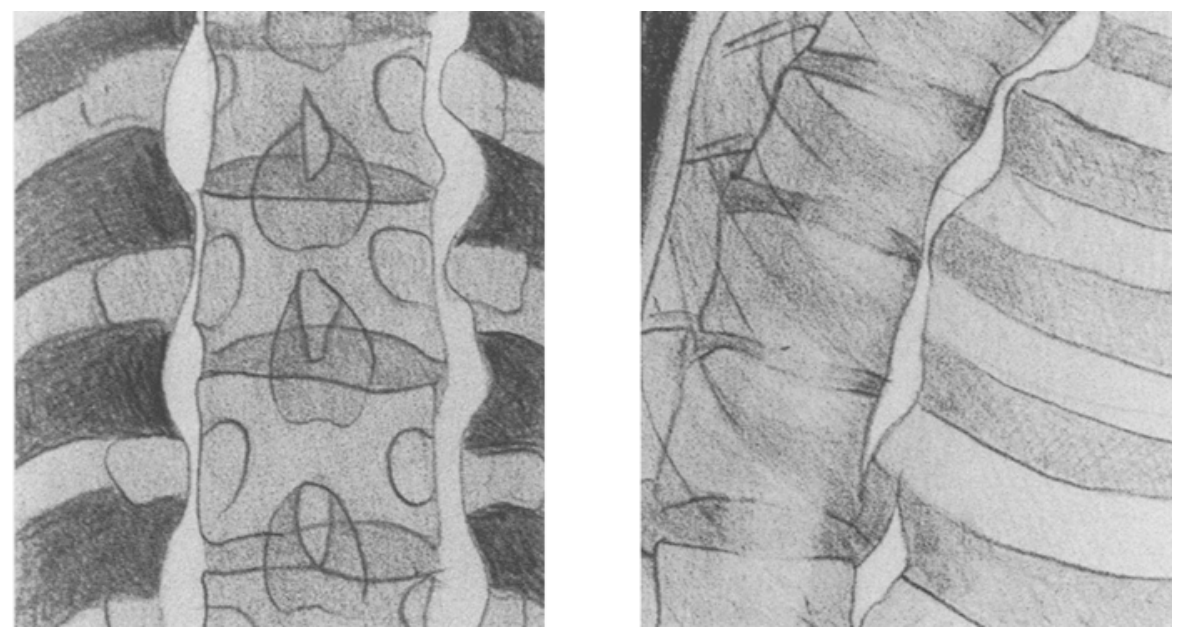

\section{G178-179}

Diffuse idiopathic skelettal hyperostosis (DISH) (dorsal vertebra) (P) (RX)

Hyperostose squelettique idiopathique diffuse (DISH) (vertèbre dorsal) (P) (RX)

Idiopatische diffuse Wirbelsäulenhyperostose (DISH) (Burstwirbel) (P) (Rö)

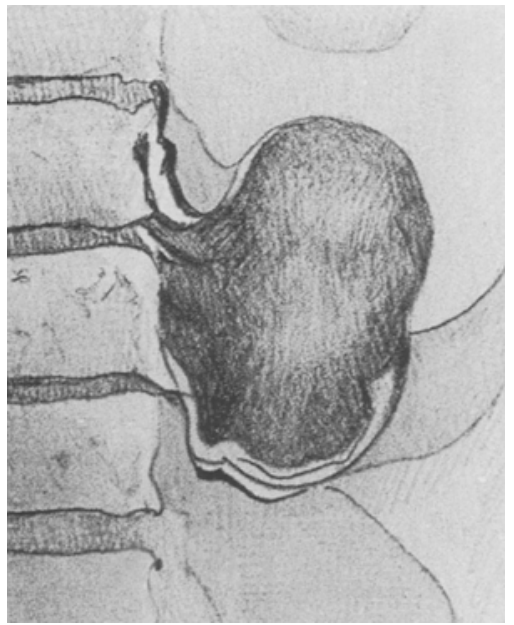

G23

Retroperitoneal schwannoma with compression of the psoas and connected to the lumbar roots (P) (IRM - T1) Schwannome lombaire rétropéritonéal comprimant le psoas et relié aux racines lombaires (P) (IRM - T1)

Schwannom im retroperitonealen Raum mit Kompression des Psoas in Verbidung mit den Lendenwurzeln (P) (IRM - T1) 